\title{
CRESCIMENTO DE MUDAS DE Anadenanthera macrocarpa (Benth) Brenan (ANGICO -VERMELHO) EM SUBSTRATO FERTILIZADO E INOCULADO COM RIZÓBIO ${ }^{1}$
}

Luciana de Lima Brandão Chaves², José Geraldo de Araújo Carneiro³ e Deborah Guerra Barroso ${ }^{3}$

\begin{abstract}
RESUMO - Foram produzidas mudas de Anadenanthera macrocarpa (angico- vermelho) em sacos de polietileno $(18 \times 15 \mathrm{~cm})$, usando-se como meio de crescimento substrato peneirado constituído de bagaço de cana-deaçúcar e torta de filtro de usina açucareira $(3: 2, \mathrm{v}: \mathrm{v})$. Objetivou-se avaliar o efeito de adubação e inoculação com rizóbio, sobre a qualidade das mudas. Instalaram-se dois experimentos, conduzidos em delineamento inteiramente casualizado, com três repetições, sendo adicionado em cada um, separadamente, o sulfato de amônio e o nitrato de amônio, em diferentes doses. Aos 180 dias após a semeadura, as mudas foram avaliadas em altura (H), diâmetro do colo (D), relação H/D, pesos de matéria seca do sistema radicular e da parte aérea, área foliar e o potencial de regeneração de raízes das mudas. Concluiu-se que a inoculação com rizóbio foi suficiente para a produção de mudas de angico nesse substrato e a fertilização estudada não trouxe ganhos ao crescimento das mudas.
\end{abstract}

Palavras-chave: Adubação, qualidade de mudas, características morfológicase rizóbio.

\section{GROWTH OF Anadenanthera macrocarpa (Benth) Brenan -RED ANGICO- SEEDLINGS IN A FERTILIZED SUBSTRATE WITH RHIZOBIUM INOCULATION}

\begin{abstract}
Seedlings of Anadenanthera macrocarpa (red angico) were grown in $18 \times 15 \mathrm{~cm}$ black polyethylene bags. The growth medium was sieved and mixed with residues of sugarcane bagasse + decomposed filter cake $(3: 2, v: v)$ The objective was the evaluation of the fertilization and inoculation with Rhizobium on the quality of the seedlings. Two experiments were carried out. In each one, separately, ammonium sulfate and ammonium nitrate were added, in three different doses. In both experiments, a specific Rhizobium species was also inoculated together with the seeds. A completely randomized design with three replicates was used. At 180 days after sowing, the seedlings were evaluated for height $(H)$, root collar diameter $(D), H / D$ ratio, shoot and root dry matter weights, leaf area and root regeneration potential. It was concluded that inoculation with Rhizobium was sufficient to stimulate growth of "red-angico" seedlings in this substrate. The tested fertilizers were not efficient for the stimulation of seedling growth.
\end{abstract}

Keywords: fertilization, quality of seedlings, morphological characteristics and Rhizobium.

\footnotetext{
${ }^{1}$ Recebido em 08.09.2005 e aceito para publicação em 13.09.2006.

${ }^{2}$ Progrma de Pós-Graduação em Produção Vegetal do CCTA/UENF.

${ }^{3}$ Setor de Silvicultura do CCTA/UENF. Av. Alberto Lamego, 2000, Parque Califórnia, 28013-602 Campos dos GoytacazesRJ.E-mail: <carneiro@uenf.br>e < deborah@uenf.br>.
} 


\section{INTRODUÇÃO}

Espécies pioneiras, quando utilizadas na revegetação de áreas degradadas, possibilitam o posterior estabelecimento de outras espécies, a estabilização e o aumento da atividade biológica do solo (PRALON, 1999). A Anadenanthera macrocarpa (Benth) Brenan (angico-vermelho) pertence, no estudo de sucessão, ao grupo das secundárias iniciais (NAVES et al., 1997, citados por CARVALHO, 2003). É uma espécie heliófita, e sua regeneração natural é expressiva, ocorrendo basicamente por meio de sementes (BORGES et al., 1991; CARVALHO, 2003). Surge espontaneamente, em freqüência e intensidade, na região norte fluminense, inclusive em todas as áreas degradadas por extração de argila (SAMÔR, 1999).

No estudo sobre a qualidade de substrato, produziram-se mudas de Eucalyptus grandis e Saccharum spp. (MORGADO, 1998) e de Anadenanthera macrocarpa e Sesbania virgata (SAMÔR, 1999). Esses autores consideraram adequada a mistura de $60 \%$ de bagaço de cana-de-açúcar e $40 \%$ de torta de filtro de usina açucareira (v:v). Entretanto, alguns autores observaram clorose em mudas de outras espécies, durante a fase inicial de viveiro, indicando uma possível limitação no fornecimento de $\mathrm{N}$ pelo substrato utilizado. A abundância da revegetação espontânea na região norte fluminense pelo angico-vermelho e os resultados observados por Barroso et al. (1998a) e Leles et al. (1998) motivaram a instalação deste experimento, utilizando-se o mencionado substrato.

Entre os adubos nitrogenados, o sulfato de amônio e o nitrato de amônio são mais freqüentemente utilizados.

Os critérios empregados pelos pesquisadores, na avaliação da qualidade de mudas, são baseados em características morfológicas de crescimento, como a altura da parte aérea $(\mathrm{H})$, diâmetro do colo (D), relação H/D, área foliar e peso de matéria seca (CARNEIRO, 1995). No entanto, o número e comprimento de raízes, sobrevivência e crescimento das mudas, após o plantio, são ressaltados por Böhm (1979). Espécies da família Leguminosae, associadas com rizóbio, têm a capacidade de fixar biologicamente o $\mathrm{N}$ da atmosfera, podendo fornecer às plantas de $60 \mathrm{a} 100 \%$ de suas necessidades desse elemento (COSTA JÚNIOR, 1997). Essa simbiose converte e transfere esse nutriente para a planta, em formas assimiláveis, mediante a atuação do rizóbio, num processo denominado Fixação Biológica do Nitrogênio (FBN) (FRANCO, 1996).

Este trabalho teve como objetivo avaliar: a) a qualidade de mudas de angico-vermelho adubadas com dois fertilizantes, sulfato de amônio e nitrato de amônio nas mesmas doses, para se obterem informações relacionadas às diferentes concentrações de $\mathrm{N}$, aplicadas ao substrato formulado com bagaço de cana-de-açúcar e torta de filtro de usina açucareira; e b) a influência da inoculação com rizóbio específico.

\section{MATERIAL E MÉTODOS}

As sementes foram obtidas no Setor de Silvicultura da UFV, sendo armazenadas em câmara fria a $5^{\circ} \mathrm{C}$, no Centro de Ciências e Tecnologias Agropecuárias/UENF. Nos tratamentos previstos, as sementes foram umedecidas para facilitar a aderência e, a seguir, inoculadas com Rhizobium sp., estirpe BR 9001, proveniente da EMBRAPAAgrobiologia, Seropédica, RJ, nos tratamentos em que sua presença foi programada.

O substrato utilizado foi constituído por bagaço de cana-de-açúcar e torta de filtro de usina açucareira (3:2; v:v), conforme utilizado por Morgado (1998) e Samôr (1999). Os componentes dos substratos foram secados ao sol e processados em peneiras com malha de $0,5 \mathrm{~cm}$. Após a mistura dos dois componentes, o substrato foi tratado com brometo de metila, na dose de $60 \mathrm{~mL}$ x $1.500 \mathrm{~L}^{-1}$ de substrato, e coberto durante $72 \mathrm{~h}$. Posteriormente, foi revolvido periodicamente para a completa remoção dos resíduos dos gases. A semeadura foi realizada no mês de setembro de 2000, diretamente no substrato, colocando-se uma semente por saco de polietileno preto com dimensões de $18 \mathrm{~cm}$ de altura e $15 \mathrm{~cm}$ de diâmetro do colo. O substrato não sofreu processo de compostagem.

Amostras do substrato foram submetidas à digestão sulfúrica e nítrico-perclórica, para determinação dos nutrientes (Quadro 1).

O valor do $\mathrm{pH}$ determinado em água (1:2,5) foi de 6,7.

Optou-se, neste trabalho, em manter as mesmas doses, dos fertilizantes utilizados, para obter as diferentes concentrações do N. Não se realizou análise química da mistura após a aplicação dos fertilizantes, visto que a qualidade do substrato não faz parte do objetivo deste estudo. 
Quadro 1 - Análise química do substrato (bagaço de cana-de-açúcar + torta de filtro (3:2, v:v)

Table 1 -Chemical analysis of the substrate (sugarcane bagasse + decomposed filter cake (3:2,v:v)

\begin{tabular}{|c|c|c|c|c|c|c|c|c|c|c|}
\hline $\begin{array}{l}\mathrm{U} \\
\%\end{array}$ & $\begin{array}{c}\mathrm{N} \\
\mathrm{Gdm}^{-3}\end{array}$ & $\mathrm{P}_{2} \mathrm{O}_{5}$ & $\underset{-3}{\mathrm{~K}_{2} \mathrm{O}}$ & \multirow{2}{*}{$\begin{array}{c}\begin{array}{c}\mathrm{C} \\
\mathrm{g} \mathrm{dm}^{-3}\end{array} \\
186,8\end{array}$} & \multicolumn{2}{|c|}{$\begin{array}{lr}\mathrm{Ca} & \mathrm{Mg} \\
\mathrm{cmol}_{\mathrm{c}} \mathrm{dm}^{-3}\end{array}$} & \multicolumn{4}{|c|}{$\mathrm{mg} \mathrm{dm}^{-3}$} \\
\hline 19,5 & 10,2 & 17,9 & 3,1 & & 73 & 15,83 & 18410 & 34 & 162,5 & 730,5 \\
\hline
\end{tabular}

Instalaram-se dois experimentos independentes, estando cada um relacionado a um fertilizante nitrogenado. Foi utilizado um delineamento inteiramente casualizado, com três repetições, contendo 90 mudas por parcela.

EXPERIMENTO A: 1) sem inoculação de rizóbio; 2) com inoculação de rizóbio; 3 ) com inoculação de rizóbio + $25 \mathrm{mg}$ de sulfato de amônio . $\mathrm{dm}^{-3} \mathrm{de}$ substrato; 4) com inoculação de rizóbio + $50 \mathrm{mg}$ de sulfato de amônio . $\mathrm{dm}^{-3}$ de substrato; e 5) com inoculação de rizóbio $+75 \mathrm{mg}$ de sulfato de amônio. $\mathrm{dm}^{-3}$ de substrato.

EXPERIMENTO B: 1) sem inoculação de rizóbio; 2) com inoculação de rizóbio; 3 ) com inoculação de rizóbio + $25 \mathrm{mg}$ de nitrato de amônio. $\mathrm{dm}^{-3}$ de substrato; 4) com inoculação de rizóbio $+50 \mathrm{mg}$ de nitrato de amônio . $\mathrm{dm}^{-3}$ de substrato; e 5) com inoculação de rizóbio + $75 \mathrm{mg}$ de nitrato de amônio. $\mathrm{dm}^{-3}$ de substrato.

O período para a produção das mudas, em ambos os experimentos, foi de 180 dias. As mudas permaneceram na casa de vegetação, totalmente revestida por filme plástico incolor, de polietileno, por 41 dias. Posteriormente, foram transferidas para área sombreada (tela de sombreamento de 50\%) por 90 dias e, a seguir, para condições de pleno sol, onde permaneceram por mais 49 dias. A irrigação foi realizada manualmente, de forma homogênea e diariamente, em todas as três fases. Ao final do período, as mudas foram avaliadas, tomando-se as medidas de altura $(\mathrm{H})$, diâmetro do colo (D), relação H/D, peso de matéria seca da parte aérea (PSA) e do sistema radicular (PSR) e área foliar (AF). Para avaliação de área foliar (AF), foi utilizado o medidor de área foliar de bancada (LI-3000, LI-COR Inc.), sendo tomadas aleatoreamente, por sorteio com números, cinco mudas da área útil da parcela. Observou-se que as mudas sorteadas apresentaram, visualmente, diâmetros do colo mais próximos ao da média. As partes aérea e radicular foram separadas e colocadas em estufa de circulação forçada a $75^{\circ} \mathrm{C}$, durante $72 \mathrm{~h}$, para determinação do peso de matéria seca (BÖHM, 1979).
Também, foi avaliado o Potencial de Regeneração de Raízes (PRR), usando-se dois tipos de rizotrons: aquários, com solução nutritiva, e tubos plásticos transparentes, com substrato sólido, segundo a metodologia descrita por Böhm (1979) e Carneiro (1995). De acordo com essa técnica, todas as raízes secundárias das mudas amostradas, lavadas e podadas a uma distância-padrão de $2,5 \mathrm{~cm}$ da raiz pivotante. A seguir, foram transplantadas nos rizotrons, onde o crescimento das raízes foi avaliado pelo número, e pelos comprimentos total e médio das raízes regeneradas. Assim, 15 dias após o transplantio para os aquários, as mudas foram retiradas e as raízes regeneradas, a partir dos pontos da poda, sendo avaliadas em número e comprimentos total e médio. A solução nutritiva, conforme Bolles Jones (1954), foi utilizada nos aquários, com $50 \%$ da concentração original e pH 5,5. A manutenção da oxigenação da solução foi assegurada por meio de uma bomba de aeração em cada aquário.

Nos tubos, foi feita a contagem do número de extremidades de raízes regeneradas e medido o comprimento das raízes. Nesse rizotrom, o substrato utilizado foi areia e solo argiloso, proveniente de uma cava de extração de argila (3:2, v:v), cuja análise química se encontra no Quadro 2. O uso desse substrato deveuse à maior facilidade de visualização das extremidades das raízes regeneradas que tocam, internamente, a parede interna do tubo.

Os dados, quanto às pressuposições para a análise de variância, foram transformados em $\log (X+10)$ para as variáveis do PRR.

Esses experimentos foram implantados em delineamento inteiramente casualizado, com quatro repetições nos aquários e cinco nos tubos. Cada repetição foi composta por uma única muda.

Os dados foram submetidos à análise de variância e as médias comparadas aatravés do teste de Tukey $(5 \%)$.

R. Árvore, Viçosa-MG, v.30, n.6, p.911-919, 2006 
Quadro 2 - Análise química do substrato (areia + argila, 3:2, v:v)

Table 2 - Chemical analysis of the substrate (sand + soil from clay extraction area-3:2, v:v)

\begin{tabular}{|c|c|c|c|c|c|c|c|c|c|c|}
\hline $\mathrm{PH}$ & $\mathrm{P}^{1}$ & $\mathrm{~K}^{1}$ & $\mathrm{Ca}$ & $\mathrm{Mg}$ & $\mathrm{Al}$ & $\mathrm{H}+\mathrm{Al}$ & $\mathrm{Fe}$ & $\mathrm{Cu}$ & $\mathrm{Zn}$ & $\mathrm{Mn}$ \\
\hline & \multicolumn{2}{|c|}{$\mathrm{mg} \mathrm{dm}^{-3}$} & \multicolumn{4}{|c|}{$\mathrm{cmol}^{\mathrm{dm}^{-3}}$} & \multicolumn{4}{|c|}{$\mathrm{mg} \mathrm{dm}^{-3}$} \\
\hline 6,4 & 42 & 41 & 1,9 & 0,6 & 0 & 1,2 & 70 & 1,2 & 5,4 & 17,5 \\
\hline $\mathrm{C}$ & $\mathrm{MO}$ & S.B. & $\mathrm{T}$ & $\mathrm{T}$ & $\bar{M}$ & $\mathrm{~V}$ & & & & \\
\hline$\%$ & $\mathrm{~g} \mathrm{dm}^{-3}$ & & $\mathrm{cmol}_{\mathrm{c}} \mathrm{dm}^{-3}$ & & & & & & & \\
\hline 0,52 & 9 & 2,7 & 3,9 & 2,7 & 0 & 69 & & & & \\
\hline
\end{tabular}

${ }^{1}$ Extrator Carolina do Norte.

\section{RESULTADOS E DISCUSSÃO}

\subsection{EXPERIMENTOA: Efeito do sulfato de amônio}

\subsubsection{Avaliação das variáveis biométricas}

No Quadro 3, mostra-se que no tratamento em que as sementes foram inoculadas e não houve adubação no substrato as mudas alcançaram maiores valores de altura (H), diâmetro do colo (D), relação H/D e área foliar, significativamente diferentes, em relação aos demais tratamentos. ON pode ser considerado o nutriente mais limitante para a produção das culturas, exceto das leguminosas (SAMPAIO et al., 1995). Chaves et al. (2003), trabalhando com Sesbania virgata e com o mesmo substrato, com adição de uréia, sulfato de amônio e nitrato de amônio e inoculação com rizóbio, chegaram a resultados semelhantes aos do presente experimento. Esses autores concluíram que somente a inoculação foi suficiente, não sendo necessária a adição de $\mathrm{N}$ em diferentes fontes ou doses.

A aplicação de $\mathrm{N}$ a substratos geralmente promove expressivos aumentos no crescimento de mudas, maior controle sobre o ritmo de crescimento, tamanho e vigor, contribuindo para que a empresa florestal possa cumprir melhor o seu cronograma de plantio (NEVES et al., 1990). Ainda de acordo com esses autores, aspectos importantes no que se refere à adubação nitrogenada estão relacionados à forma de $\mathrm{N}$ e às suas doses recomendáveis. $\mathrm{Na}$ avaliação do efeito da adubação desse substrato para a produção de mudas de Schinus terebenthifolius e Mimosa caesalpiinifolia, Barroso et al. (1998b) confirmaram ser o $\mathrm{N}$ o único nutriente limitante durante o período de crescimento, resultado não observado com os dados do presente experimento. Em trabalho com o mesmo substrato, mas com mudas de Sesbania virgata, Barroso et al. (2000) encontraram resultados diferentes dos aqui observados, pois o incremento de doses de $\mathrm{N}$ possibilitou maior aumento em altura, diâmetro do colo e área foliar. Inconsistências entre resultados de experimentos podem estar relacionadas com as condições edafoclimáticas da metodologia de produção de mudas ou diferentes exigências entre espécies, o que pode justificar as diferenças obtidas entre distintos experimentos (SOUTH, 2000).

Quadro 3 - Altura $(H-c m)$, diâmetro do colo $(\mathrm{D}-\mathrm{mm})$ relação H/D, área foliar $(\mathrm{AF}-\mathrm{cm} 2)$, pesos de matéria seca (g) do sistema radicular (PSR), da parte aérea (PSA) e total (PST) e relação PSR/PSA das mudas de Anadenanthera macrocarpa (angico-vermelho), inoculadas (I) e não-inoculadas (NI) com rizóbio e fertilizadas com diferentes doses de sulfato de amônio, 180 dias após a semeadura

Table 3 - Height $(H-c m)$, root collar diameter $(D-m m), H / D$ ratio, leaf area $(A F-c m 2)$, dry matter weight $(g)$ of the root system (PSR), stem (PSA) and total weight (PST) with Rhizobium inoculated(I) and not inoculated (NI) Anadenanthera macrocarpa seedlings, fertilized with different doses of ammonium sulfate and, 180 days after sowing

\begin{tabular}{lcccccccc}
\hline \multicolumn{1}{c}{ TRAT } & $\mathrm{H}$ & $\mathrm{D}$ & $\mathrm{H} / \mathrm{D}$ & $\mathrm{AF}$ & PSR & PSA & PST & PSR/PSA \\
\hline $\mathrm{NI}+0 \mathrm{mg} \cdot \mathrm{dm}^{-3}$ & $16,94 \mathrm{~b}$ & $3,36 \mathrm{~b}$ & $4,91 \mathrm{a}$ & $53,80 \mathrm{bc}$ & $0,93 \mathrm{~b}$ & $1,26 \mathrm{~b}$ & $2,19 \mathrm{~b}$ & $0,89 \mathrm{a}$ \\
$\mathrm{I}+0 \mathrm{mg} \cdot \mathrm{dm}^{-3}$ & $29,19 \mathrm{a}$ & $5,43 \mathrm{a}$ & $5,45 \mathrm{a}$ & $95,33 \mathrm{a}$ & $3,35 \mathrm{a}$ & $3,26 \mathrm{a}$ & $6,61 \mathrm{a}$ & $1,06 \mathrm{a}$ \\
$\mathrm{I}+25 \mathrm{mg} \cdot \mathrm{dm}^{-3}$ & $8,75 \mathrm{c}$ & $2,47 \mathrm{c}$ & $3,44 \mathrm{~b}$ & $65,43 \mathrm{ab}$ & $1,07 \mathrm{~b}$ & $1,27 \mathrm{~b}$ & $2,34 \mathrm{~b}$ & $0,91 \mathrm{a}$ \\
$\mathrm{I}+50 \mathrm{mg} \cdot \mathrm{dm}^{-3}$ & $7,53 \mathrm{c}$ & $2,02 \mathrm{~d}$ & $3,71 \mathrm{~b}$ & $25,28 \mathrm{c}$ & $0,34 \mathrm{c}$ & $0,39 \mathrm{c}$ & $0,73 \mathrm{c}$ & $0,99 \mathrm{a}$ \\
$\mathrm{I}+75 \mathrm{mg} \cdot \mathrm{dm}^{-3}$ & $*$ & $*$ & $*$ & $*$ & $*$ & $*$ & $*$ & $*$ \\
CV $(\%)$ & 10,013 & 3,346 & 10,338 & 24,498 & 15,743 & 21,175 & 16,707 & 25,818 \\
\hline
\end{tabular}

Médias seguidas da mesma letra na coluna não diferem entre si, pelo teste de Tukey (5\% de probabilidade).

* Não houve sobrevivência das mudas.

R. Árvore, Viçosa-MG, v.30, n.6, p.911-919, 2006 
Os tratamentos que tiverem inoculação com rizóbio e aplicação de adubação não indicaram ganho de crescimento em altura e em diâmetro do colo. Essa constatação pode ser explicada pelo fato de que, estando o substrato em fase de compostagem, os microrganismos decompositores têm tido maior vantagem, na competição por $\mathrm{N}$, que as mudas na absorção desse nutriente, prejudicando o crescimento destas (CARNEIRO, 1995). Materiais orgânicos ainda não decompostos são ricos em $\mathrm{C}$, o que acarreta uma relação $\mathrm{C} / \mathrm{N}$ elevada, fato que pode ter ocorrido durante o período de produção das mudas, propiciando imobilização do N pelos microorganismos, causando deficiência desse nutriente para as mudas (SOUTH e DAVEY, 1983; MAY, 1984, citados por CARNEIRO, 1995). Segundo Siqueira e Moreira (2001), pequenas doses podem beneficiar a FBN, atuando como estimuladoras do crescimento em certas espécies, principalmente as que apresentam nodulação tardia ou fixam $\mathrm{N}$ durante curto período do seu ciclo, o que pode, eventualmente, ser o caso presente. Portanto, pode-se inferir que o $\mathrm{N}$ aplicado possa ter sido absorvido pelo rizóbio, em detrimento das mudas. Nesse caso, pode ser que as doses utilizadas não tenham sido suficiente para suprir a demanda das exigências por $\mathrm{N}$ pelos microrganismos e pelas mudas.

O diâmetro do colo, combinado com a altura, é vinculado ao vigor de mudas, pela estreita correlação ao crescimento radicular (CARNEIRO, 1995; JOSÉ, 2003). Essa assertiva é compatível com os resultados observados no Quadro 3, onde se observa que o tratamento que recebeu apenas a inoculação com rizóbio exibe valores de características morfológicas que melhor indica a qualidade das mudas. A relação H/D também apresenta diferença estatística entre os tratamentos com fertilizantes quando comparados com os nãoadubados. Valores mais elevados foram encontrados onde não houve adição do sulfato de amônio, independentemente da inoculação com rizóbio. Essa relação exprime o equilíbrio de crescimento das mudas, pois conjuga duas características de qualidade de mudas em só um índice (CARNEIRO, 1995). Esse autor relatou que o valor dessa relação, durante o período de crescimento de Pinus taeda no viveiro, oscilou entre os limites de 5,4 até 8,1, valor encontrado no tratamento inoculado com rizóbio no presente experimento.

Não houve sobrevivência das mudas no tratamento em que se adicionaram $75 \mathrm{mg}$ de sulfato de amônio ao substrato, não tendo sido encontrado amparo na literatura que justifique essa mortalidade.

Em trabalho com mudas de Sesbania virgata, contrariamente ao observado no presente estudo (Quadro 3), Barroso et al. (2000) encontraram crescentes médias de peso de matéria seca aérea e radicular, com o aumento de doses de nitrato de amônio. A relação PSR/PSA mostrou equivalência entre todos os tratamentos.

\subsubsection{Avaliação do potencial de regeneração de raízes}

Pela análise do Quadro 4, observou-se que, com referência ao número e comprimento de raízes regeneradas nos aquários, somente as mudas originadas de sementes inoculadas e adubadas com $50 \mathrm{mg} \cdot \mathrm{dm}^{-3}$ apresentaram diferença significativa em relação aos demais tratamentos, que não mostraram diferenças.

Quadro 4-Número (N), comprimento total $(\mathrm{C}-\mathrm{cm})$ e comprimento médio $(\mathrm{CM})$ de raízes regeneradas (15 dias após o transplantio para aquário), número de extremidades de raízes novas (NEN) e comprimento de raízes novas (CRN - cm) das mudas de Anadenanthera macrocarpa (angico-vermelho) inoculadas (I) e não-inoculadas (NI) com rizóbio e fertilizadas com diferentes doses de sulfato de amônio 15 dias após o transplantio para os tubos plásticos

Table 4 -Number $(N)$, total length $(C-\mathrm{cm})$ and average length $(C M)$ of the regenerated roots, (15 days after the transplanting to the glass containers) and number of new tips (NEN), new root length (CRN) of Anadenanthera macrocarpa seedlings inoculated with Rhizobium (I), not inoculated (NI) and fertilized with different doses of ammonium sulfate, 15 days after the transplanting to the glass containers

\begin{tabular}{ccccr}
\hline \multicolumn{1}{c}{ TRAT } & $\mathrm{N}$ & $\mathrm{C}$ & $\mathrm{CM}$ & $\mathrm{NEN}$ \\
\hline $\mathrm{NI}+0 \mathrm{mg} \mathrm{dm}^{-3}$ & $162,00 \mathrm{a}$ & $568,62 \mathrm{a}$ & $3,30 \mathrm{a}$ & $93,6000 \mathrm{~b}$ \\
$\mathrm{I}+0 \mathrm{mg} \mathrm{dm}^{-3}$ & $488,00 \mathrm{a}$ & $493,50 \mathrm{a}$ & $50,8000 \mathrm{~b}$ \\
$\mathrm{I}+25 \mathrm{mg} \mathrm{dm}^{-3}$ & $102,00 \mathrm{a}$ & $360,95 \mathrm{a}$ & $1,96 \mathrm{a}$ & $162,8000 \mathrm{a}$ \\
$\mathrm{I}+50 \mathrm{mg} \mathrm{dm}^{-3}$ & $33,50 \mathrm{~b}$ & $81,72 \mathrm{~b}$ & $3,10 \mathrm{a}$ & $58,0000 \mathrm{~d}$ \\
$\mathrm{I}+75 \mathrm{mg} \mathrm{dm}^{-3}$ & $*$ & $*$ & $0,61 \mathrm{~b}$ & $32,8000 \mathrm{~d}$ \\
$\mathrm{CV}(\%)$ & 32,524 & 33,414 & $*$ & $35,4000 \mathrm{c}$ \\
\hline
\end{tabular}

Médias seguidas da mesma letra na coluna não diferem entre si, pelo teste de Tukey (5\% de probabilidade)

* Não houve sobrevivência das mudas. 
A dose de $50 \mathrm{mg}$ de sulfato de amônio originou mudas com os menores valores de número e comprimento (total e médio) de raízes regeneradas. O mesmo foi verificado na avaliação de altura, diâmetro do colo, área foliar e peso de matéria seca (Tabela 3), evidenciando-se a compatibilidade entre as avaliações das características morfológicas com o PRR., como constatado por Morgado (1998). Raízes dependem da parte aérea das mudas para o suprimento inicial de carbono, não se podendo negar a influência dessa parte sobre o crescimento do sistema radicular (CARNEIRO, 1995).

No Quadro 4, mostra-se que o maior comprimento e número de extremidades de raízes novas regeneradas, nos testes de PRR realizados nos tubos, foram encontrados nas mudas que somente foram inoculadas com o rizóbio específico, resultado compatível com os anteriores. Essas duas características de crescimento radicular são importantes, pois geralmente fornecem a densidade de enraizamento (BÖHM, 1979).

Nota-se que a adubação com sulfato de amônio não propiciou ganhos às mudas, podendo-se inferir que as doses do adubo não tenham sido suficientes, com vistas à nutrição das mudas, mas usadas para o consumo pelos microrganismos. Não se encontraram na literatura mais referências sobre a aplicação de adubação nitrogenada e seus efeitos no PRR, usando-se rizotrons como instrumento de medição de crescimento de raízes.

\subsection{EXPERIMENTO B: Efeito de nitrato de amônio}

\subsubsection{Avaliação das variáveis biométricas}

Pelo Quadro 5, observa-se que as maiores médias de altura e diâmetro do colo foram obtidas com o tratamento em que se inocularam as sementes com rizóbio e não se aplicou o nitrato de amônio ao substrato, diferindo significativamente dos demais tratamentos. Entretanto, as áreas foliares dos tratamentos adubados mostraram maiores valores, significativamente diferentes, em relação aos com e sem inoculação com rizóbio. Tais resultados diferiram quando o adubo aplicado foi o sulfato de amônio (Quadro 3). Essa diferença pode ser atribuída à concentração do nutriente $\mathrm{N}$ no nitrato de amônio, que é superior ao do sulfato de amônio. A área foliar dos tratamentos adubados apresentou maiores médias em relação aos sem adubação, independentemente de estarem as mudas inoculadas com rizóbio ou não. Observou-se, ainda, que o resultado foi crescente à medida que as doses foram aumentadas. Provavelmente essas diferenças, em relação aos tratamentos não fertilizados, não tenham sido detectadas estatisticamente, em função do alto coeficiente de variação dos dados. Segundo Carneiro (1995) e Barroso et al. (1998a), áreas foliares maiores podem implicar problemas após o plantio, devido à maior transpiração das mudas, principalmente se as plantas apresentarem altura e diâmetro do colo menores, e acarretar alta porcentagem de mortalidade no campo, como foi constatado no presente estudo. Assim, maior área foliar não implica mudas com maiores médias de altura e diâmetro do colo e com melhores chances de sobrevivência após o plantio.

Esses resultados apontam a tendência de ser somente a inoculação das sementes o suficiente para se obterem mudas de qualidade, pois o nitrato de amônio não proporcionou médias, nem de altura e nem de diâmetro do colo, maiores que das mudas do tratamento cujas sementes foram inoculadas e não receberam adição de N. Esses resultados podem ser devidos à fonte de aplicação, que afeta o processo de formação e desenvolvimento dos nódulos. O nitrato de amônio inibiu completamente a formação dos nódulos em Acacia mangium (JACOB NETO et al., 1998). A avaliação do efeito da adubação do mesmo substrato utilizado no presente experimento para produção de mudas de Schinus terebinthifolius e de Mimosa caesalpiniifolia indicou ser o $\mathrm{N}$ o único nutriente limitante durante o período de crescimento no viveiro (BARROSO et al., 1998 b).

No Quadro 5, apresentam-se as médias dos pesos de matéria seca das mudas. Apenas o sistema radicular sofreu influência dos tratamentos, refletindo no peso de matéria seca total. Entretanto, não foram observadas diferenças entre os tratamentos na relação PSR/PSA como nos demais. Novamente, observaram-se comportamentos distintos entre as duas fontes de N, em razão, provavelmente, das diferentes concentrações do mesmo nutriente, em cada um deles. Consideram-se, nesse experimento, ser dispensáveis análises nesse particular, tendo em vista que nenhum deles apresentou influência nos valores que expressam a qualidade de mudas.

Vários trabalhos apresentando valores mais elevados de diâmetro do colo estão correlacionados com maiores quantidades de raízes (CARNEIRO, 1995). Essa correlação também foi constatada no presente estudo, em ambos os experimentos. Observou-se, também, que o tratamento com sementes inoculadas com rizóbio e sem adubação atingiu o maior valor de PSR, resultado compatível com os anteriormente constatados. 
Quadro 5 - Altura $(\mathrm{H}-\mathrm{cm})$, diâmetro do colo $(\mathrm{D}-\mathrm{cm})$, relação H/D, área foliar $(\mathrm{AF})$, peso médio de matéria seca (g) do sistema radicular (PSR), da parte aérea (PSA) e total (PST) e relação (PSR/PSA) das mudas de Anadenanthera macrocarpa (angico-vermelho) inoculadas (I) e não-inoculadas (NI) com rizóbio e submetidas a diferentes doses de nitrato de amônio, 180 dias após a semeadura

Table 5 - Height $(H-c m)$, root collar diameter $(D-m m), H / D$ ratio, leaf area $\left(A F-c^{2}\right)$, dry matter weight $(g)$ of the root system (PSR), stem (PSA) and total weight (PST) with Rhizobium inoculated (I) and not inoculated (NI) Anadenanthera macrocarpa seedlings, fertilized with different doses of ammonium nitrate, 180 days after sowing

\begin{tabular}{ccccccccc}
\hline TRAT & H & D & H/D & AF & PSR & PSA & PST & PSR/PSA \\
\hline $\mathrm{NI}+0 \mathrm{mg} \mathrm{dm}^{-3}$ & $16,94 \mathrm{bc}$ & $3,36 \mathrm{bc}$ & $4,91 \mathrm{a}$ & $53,80 \mathrm{~b}$ & $0,93 \mathrm{~b}$ & $41,26 \mathrm{a}$ & $2,19 \mathrm{~b}$ & $0,89 \mathrm{a}$ \\
$\mathrm{I}+0 \mathrm{mg} \mathrm{dm}^{-3}$ & $29,19 \mathrm{a}$ & $5,43 \mathrm{a}$ & $5,45 \mathrm{a}$ & $95,33 \mathrm{~b}$ & $3,35 \mathrm{a}$ & $69,93 \mathrm{a}$ & $6,61 \mathrm{a}$ & $1,06 \mathrm{a}$ \\
$\mathrm{I}+25 \mathrm{mg} \mathrm{dm}^{-3}$ & $10,97 \mathrm{c}$ & $2,82 \mathrm{c}$ & $3,84 \mathrm{a}$ & $121,20 \mathrm{ab}$ & $2,15 \mathrm{ab}$ & $42,17 \mathrm{a}$ & $4,32 \mathrm{ab}$ & $0,95 \mathrm{a}$ \\
$\mathrm{I}+50 \mathrm{mg} \mathrm{dm}^{-3}$ & $17,90 \mathrm{~b}$ & $3,48 \mathrm{~b}$ & $5,25 \mathrm{a}$ & $173,52 \mathrm{ab}$ & $3,16 \mathrm{a}$ & $29,82 \mathrm{a}$ & $6,31 \mathrm{a}$ & $0,98 \mathrm{a}$ \\
$\mathrm{I}+75 \mathrm{mg} \mathrm{dm}^{-3}$ & $14,85 \mathrm{bc}$ & $3,42 \mathrm{~b}$ & $4,39 \mathrm{a}$ & $229,58 \mathrm{a}$ & $1,82 \mathrm{ab}$ & $18,63 \mathrm{a}$ & $3,78 \mathrm{ab}$ & $0,90 \mathrm{a}$ \\
$\mathrm{CV}(\%)$ & 13,513 & 5,524 & 14,79 & 34,082 & 29,979 & 70,804 & 28,063 & 14,852 \\
\hline
\end{tabular}

Médias seguidas da mesma letra na coluna não diferem entre si, pelo teste de Tukey (5\% de probabilidade).

\subsubsection{Avaliação do potencial de regeneração de raízes (PRR)}

O PRR. avaliado nos aquários e apresentado no Quadro 6 indica que as características de qualidade apresentaram resultados incompatíveis, para os quais não foram encontradas referências bibliográficas pertinentes ao tema.

Quanto ao número de raízes regeneradas, observouse que as mudas produzidas por sementes inoculadas com rizóbio (sem nitrato de amônio) e as que receberam a maior e menor doses desse fertilizante apresentaram as médias mais elevadas, equivalendo entre si.

A comparação do comprimento total das raízes revelou que somente a média das mudas que receberam
$50 \mathrm{mg}$ de nitrato de amônio. $\mathrm{dm}^{-3}$ de substrato, com sementes inoculadas, apresentou valor inferior. As demais médias foram equivalentes. Neste experimento, constatouse que em todas as mudas as raízes regeneradas eram, em sua maioria, finas e também continham grande quantidade de pêlos absorventes. O maior comprimento médio foi verificado no tratamento com inoculação e que recebeu $25 \mathrm{mg} \cdot \mathrm{dm}^{-3}$ de substrato, equivalendose ao tratamento sem inoculação e sem fertilização, assim como ao tratamento com inoculação e adubado com $75 \mathrm{mg} / \mathrm{dm}^{-3}$. Essa observação não permitiu deduções, pois, segundo Carneiro (1995), nenhuma característica pode ser tomada, individualmente, como parâmetro de qualidade, mas é um conjunto de resultados que aponta a indicação de qualidade de mudas.

Quadro 6 - Número $(\mathrm{N})$, comprimento total $(\mathrm{C}-\mathrm{cm})$ e comprimento médio $(\mathrm{CM})$ de raízes regeneradas $(15$ dias após o transplantio para aquário), número de extremidades de raízes novas (NEN) e comprimento de raízes novas $(\mathrm{CRN}-\mathrm{cm})$ das mudas de Anadenanthera macrocarpa (angico-vermelho) inoculadas (I) e não-inoculadas (NI) com rizóbio e fertilizadas com diferentes doses de nitrato de amônio, 15 dias após o transplantio para os tubos plásticos

Table 6 - Number $(N)$, total length $(C-\mathrm{cm})$ and average length $(C M)$ of the regenerated roots, $(15$ days after the transplanting to the glass containers) and number of new tips (NEN), new root length (CRN) of Anadenanthera macrocarpa seedlings inoculated with Rhizobium (I), not inoculated (NI) and fertilized with different doses of ammonium nitrate, 15 days after the transplanting to the glass containers

\begin{tabular}{|c|c|c|c|c|c|}
\hline TRAT & $\mathrm{N}$ & $\mathrm{C}$ & $\mathrm{CM}$ & NEN & $\mathrm{CRN}$ \\
\hline $\mathrm{NI}+0 \mathrm{mg} \mathrm{dm}^{-3}$ & $100,00 \mathrm{bc}$ & 363,89 a & $2,99 \mathrm{ab}$ & $50,80 \mathrm{e}$ & $93,60 \mathrm{e}$ \\
\hline $\mathrm{I}+0 \mathrm{mg} \mathrm{dm}^{-3}$ & $256,50 \mathrm{a}$ & 543,45 a & $2,08 \mathrm{bc}$ & $96,20 \mathrm{a}$ & $162,80 \mathrm{a}$ \\
\hline $\mathrm{I}+25 \mathrm{mg} \mathrm{dm}^{-3}$ & $149,00 \mathrm{ab}$ & 616,99 a & $4,23 \mathrm{a}$ & $56,80 \mathrm{~d}$ & $133,00 \mathrm{~b}$ \\
\hline $\mathrm{I}+50 \mathrm{mg} \mathrm{dm}^{-3}$ & $52,25 \mathrm{c}$ & $41,32 \mathrm{~b}$ & $0,78 \mathrm{c}$ & $73,60 \mathrm{~b}$ & $123,60 \mathrm{c}$ \\
\hline $\mathrm{I}+75 \mathrm{mg} \mathrm{dm}^{-3}$ & $198,50 \mathrm{ab}$ & 568,02 a & $2,75 \mathrm{ab}$ & $65,40 \mathrm{c}$ & $107,00 \mathrm{~d}$ \\
\hline $\mathrm{CV}(\%)$ & 8,815 & 11,03 & 2,14 & 8,853 & 8,766 \\
\hline
\end{tabular}

Médias seguidas da mesma letra na coluna não diferem entre si, pelo teste de Tukey (5\% de probabilidade). 
Mudas com maiores dimensões dos parâmetros morfológicos resultam em maiores valores de comprimento das raízes regeneradas em solução hidropônica (SAMÔR, 1999; BARROSO, 1999). Esse comportamento foi evidente neste teste, sendo coerente com os resultados encontrados pelos citados autores.

Os resultados obtidos nos testes de PRR, realizados nos tubos e apresentados no Quadro 6, indicam que as mudas originadas de sementes que somente foram inoculadas tiveram as maiores médias, tanto no número quanto no comprimento de raízes regeneradas, evidenciando a eficiência da inoculação. Essa constatação confirma os resultados apresentados na solução nutritiva dos aquários.

\section{CONCLUSÕES}

a) A inoculação das sementes com rizóbio foi suficiente para produção de mudas de angico-vermelho, não sendo necessária a adição de $\mathrm{N}$, proveniente de sulfato de amônio e nitrato de amônio, nas doses estudadas.

b) Os indicadores biométricos que conceituam a qualidade de mudas e o potencial de regeneração de raízes (número e comprimentos total e médio) apontaram que as mudas que terão maior probabilidade de sobrevivência no campo, após o plantio, provavelmente são aquelas cujas sementes foram inoculadas com rizóbio e não receberam a aplicação dos fertilizantes nitrogenados estudados.

c) Não é recomendável a aplicação de $75 \mathrm{mg}$ de sulfato de amônio. $\mathrm{dm}^{-3}$ do substrato em estudo.

\section{REFERÊNCIAS BIBLIOGRÁFICAS}

BARROSO, D.G.; LELES, P.S.S.; CARNEIRO, J.G.A. Produção de mudas de Eucalyptus camaldulensis e E. urophylla em tubetes e blocos prensados com diferentes substratos. In: REUNIÃO DE PROGRAMAÇÃO DE PESQUISADO CCTA, 5. 1998, Campos dos Goytacazes. Anais... Campos dos Goytacazes: UENF, 1998a. p 20.

BARROSO, D.G. et al. Efeitos da adubação em mudas de sabiá (Mimosa caesalpiniaefolia Benth) e aroeira (Schinus terebinthifolius Raddi) produzidas em substrato constituído por resíduos agro-industriais. Revista Árvore, v. 22, n. 4, p. 433-441, 1998 b.

R. Árvore, Viçosa-MG, v.30, n.6, p.911-919, 2006
BARROSO, D.G. Qualidade de mudas de Eucalyptus camaldulensis e Eucalyptus urophylla, produzidas em tubetes e em blocos prensados, com diferentes substratos. 1999. 83 f. Tese (Doutorado em Produção Vegetal) - Universidade Estadual do Norte Fluminense, Campos dos Goytacazes, 1999.

BARROSO, D.G. et al. Efeito de diferentes doses de nitrogênio em mudas de sesbânia (Sesbania virgata Raddi) e sabiá (Mimosa caesalpiniifolia Benth), produzidas em resíduos agro-industriais como substrato. In: FOREST 2000, Porto Seguro. Resumos Técnicos... Porto Seguro: Biosfera, 2000. p. 120-121.

BÖHM, W. Methods of studying root systems. Berlin: Springer-Verlag, 1979. 188 p.

BOLLES JONES, E.W. Nutrition of Hevea brasiliensis I. Experimental methods.

Journal Rubbler Research

International, p. 183, 1954.

BORGES, E.E.L. et al. Mobilização de reservas em sementes de angico vermelho (Piptadenia peregrina Benth) e armazenamento em diferentes recipientes e condições de ambientes. Revista Árvore, v. 15, n. 2, p. 126-136, 1991.

CARneiro, J.G.A. Produção e controle de qualidade de mudas florestais. Curitiba: UFPR:FUPEF; Campos: UENF, 1995. 451 p.

\section{CARVAlHO, P.E.R. Espécies Arbóreas}

Brasileiras. Brasília: Embrapa Informações Tecnológicas; Colombo,PR: Embrapa Florestas, 2003. $1.039 \mathrm{p}$.

CHAVES, L.L.B. et al. Efeitos da inoculação com rizóbio e da adubação nitrogenada na produção de mudas de sesbânia em substrato constituído de resíduos agroindustriais. Revista Árvore, v. 27 , n. 4, p. 443-449, 2003.

COSTA JÚNIOR, P.F. Comportamento de leguminosas arbóreas inoculadas com fungos micorrízicos arbusculares e rizóbio em estéril de argila. 1997. $64 \mathrm{f}$. Dissertação (Mestrado em Produção Vegetal) Universidade Estadual do Norte Fluminense, Campos dos Goytacazes, 1997. 
FRANCO, A. A. Fixação biológica do nitrogênio na agricultura tropical. In: ALVAREZ, V. C.;

FONTES, L.E.; FONTES, M. P. (Eds.) O solo nos grandes domínios morfoclimáticos do Brasil e o desenvolvimento sustentado. Viçosa, MG.: SBCS: UFV, DPS, 1996. p. 505-523.

JACOB NETO, J.; GOI, S.R.; SPRENT, J.I. Efeito de diferentes formas de nitrogênio na nodulação e crescimento de Acacia mangium. Floresta e Ambiente, v. 5, n. 1, p. 104-110, 1998.

JOSÉ, A. C. Utilização de mudas de espécies florestais produzidas em tubetes e sacos plásticos para revegetação de áreas degradadas. 2003. 101 f. Dissertação (Mestrado em Engenharia Florestal) - Universidade Federal de Lavras, Lavras, 2003.

LELES, P.S.S.; CARNEIRO, J.G A.; BARROSO, D.G. Comportamento de mudas de Hymenaea courbaril L. var. stilbocarpa (Haine) e Apuleia leiocarpa (Vog) Macbr. produzidas sob três regimes de irrigação. Revista Árvore, v. 22, n. 1, p. 11-19, 1998.

MORGADO, I. F. Resíduos agroindustriais prensados como substrato para a produção de mudas de Eucalyptus grandis Hill ex Maiden e Saccharum spp. 1998. 102 f. Tese (Doutorado em Produção Vegetal) Universidade Estadual do Norte Fluminense, Campos dos Goytacazes, 1998.
NEVES, J.C.L.; GOMES, J.M.; NOVAIS, R.F. Fertilização mineral de mudas de eucalipto. In: BARROS, N.F.; NOVAIS, R.F. (Eds.) Relação solo-eucalipto. Viçosa, MG, Folha de Viçosa, 1990. p. 99-126.

PRALON, A.Z. Produção de mudas de Mimosa caesalpiniaefolia, inoculadas com fungos micorrízicos arbusculares e rizóbio, em estéril de argila misturado com o resíduo Ferkal. 1999. 70 f. Dissertação (Mestrado em Produção Vegetal) - Universidade Estadual do Norte Fluminense, Campos dos Goytacazes, 1999.

SAMÔR, O.J.M. Comportamento de mudas de Sesbania virgata e Anadenanthera macrocarpa, produzidas em diferentes recipientes e substratos, destinadas à recuperação de áreas degradadas pela extração de argila. 1999. 70 f. Dissertação (Mestrado em Produção Vegetal) - Universidade Estadual do Norte Fluminense, Campos dos Goytacazes, 1999.

SAMPAIO, E.V.S.B. et al. Capacidade de suprimento de nitrogênio e resposta à fertilização de vinte solos de Pernambuco. Revista Brasileira de Ciência do Solo, v. 19, n. 2, p. 270-279, 1995.

SIQUEIRA, J. O.; MOREIRA, F. M. S. Biologia e bioquímica do solo. Lavras: Universidade Federal de Lavras, 2001. 291 p.

SOUTH, D. B. Planting morphologically improved pine seedlings to increase survival and growth. Auburn: Auburn University, 2000. 14 p. (Forestry and Wildlife Series, 1). 